\title{
Heutagogoy Extended: A Conceptual Framework to Support Informal, Self-Determined Lifelong Learning for Older Adults
}

\author{
Dirk Morrison \\ University of Saskatchewan
}

Nazreen Beaulieu

Received: June 2, 2020

Accepted: August 21, 2020

Published: August 21, 2020

doi:10.5296/jse.v10i3.17297

URL: https://doi.org/10.5296/jse.v10i3.17297

\begin{abstract}
This paper reviews and then extends the concept of heutagogy, making a case for why and how it provides a theoretical and practical framework for understanding and facilitating informal, self-determined older adults' online lifelong learning activities and processes. This discussion is situated within a unique research context, namely, older adults' (retirees) use of online personal learning networks (oPLNs) to support their informal lifelong learning goals. From our analysis, there is evidence to substantiate the claim that heutogogical principles were manifest within an "ecology" of informal online learning.
\end{abstract}

Keywords: heutagogy, online personal learning networks 


\section{Introduction}

Data from recent sources (Anderson \& Perrin, 2017a; Smith, 2016) clearly indicate the need for "push-back" regarding commonly held, but invalid and negative stereotypes of older adults as "digital immigrants" (Prensky, 2001). While, technically, simply referring to individuals born before the widespread use of digital technologies (i.e, before 1985), the underlying conceptual framework of the digital immigrant/digital native binary is suspect [Helsper \& Enyon, 2013]. For example, two core but unsubstantiated assumptions include: 1) digital immigrants are believed to be less quick to utilize new communication technologies than the so-called "digital natives," and, 2) a belief that early exposure to technology fundamentally changes the way people learn. (Techopedia, 2017). Applied to older adults (i.e., 65+), or "Third Age" learners [Weiss \& Bass, 2001], these assumptions of being a "digital immigrant" in regards to the adoption and use of information and communication technologies (ICT), devices, applications and processes can paint a cynical picture, namely, that of a somewhat mostly inept demographic. (Note: doing a simple Google Image search under "digital immigrants" results in many images of seniors). The research presented, along with other emerging findings (e.g., 65\% of adults over 60 years of age now use social media sites, a tenfold increase to the previous decade (Perrin, 2015) and, as of 2017, 82\% of older adults between 65-69 years of age report using the Internet (Anderson, M., \& Perrin, A., 2017b; Greenwood, Perrin, \& Duggan, 2017)), shows that these perpetuated misperceptions of older adults are inaccurate and possibly harmful stereotypes (Weiss \& Bass, 2001). In fact, our findings show that some older adults are very willing and able to learn about, adopt and adapt new ICTs, including the use of social media, for their informal self-directed learning purposes and are capable, competent agents within Web 2.0 (O'Reilly, 2005; Alexander, 2006) learning contexts. In particular, these older adults are active adopters of ICT for learning purposes and are a demographic that is in need of further study. What is clearly missing from the limited literature regarding older adults' use of ICT for learning, however, is the articulation of a conceptual framework in which to locate deeper explorations, understandings and interpretations of this phenomenon.

\section{The need for a new conceptual framework}

Similar to the idea that schools, for the most part, continue to operate using Web 1.0 education, namely, essentialist and instructivist strategies (Gerstein, 2013) to teach a Web 2.0 generation [i.e., co-creation, curation, production, etc.], (Alexander, 2006], older adults are actively and increasingly adopting the Internet and social media tools (Gerstein, 2013; Perrin, 2015; ), but may also be victim to Web 1.0 stereotypes; by this we mean older adults' use of ICT for learning, especially informal learning, can be perceived through the myopic lens of outdated, pre-internet conceptualizations of what, where, and how older adults engage in self-directed lifelong learning opportunities (think: locally-based clubs, social groups, libraries). However, it turns out that some older adults are, in fact, using the Internet to not only access and harvest the resources there (i.e., Web 1.0 strategies, a "consumption of resources" model) for their lifelong learning goals, but are also making connections with others to collaborate, share, curate, co-create, and learn together (i.e., adoption of Web 2.0 strategies). It is our contention that the concept of heutagogy (Hase \& Kenyon, 2000) provides a valid and robust conceptual 
framework to understand, articulate and actualize new horizons of informal, self-directed learning opportunities and learning with other older adults.

\section{Literature Review}

\section{What is heutagogy?}

The term "heutagogy," first coined by Hase and Kenyon (2000), captures the essence of the changing landscape of 21 st Century learning; it succinctly describes a form of self-directed learning that highlights the skill of learning on one's own but, importantly, also learning with technology; the latter qualifier, it is speculated, promotes increased 'learner agency' and a more autonomous, self-directed way of learning (Blaschke, 2012; Blaschke \& Hase, 2016). Heutagogy here is seen as an extension of the already well-established principles of andragogy (Smith, 2002), constructivism (Glaserfeld, 1989), self-directed learning (Caffarella, 1993), and student-centered learning (Hase \& Kenyon, 2000; Blaschke \& Hase, 2016). Additionally, these authors emphasize that learning is a innate human endeavour and is, therefore, an internal process best controlled by the learner (Hase \& Kenyon, 2000). An important tenet of heutagogy centers on the issue of control, specifically, control over the learning process, whereas pedagogy, and andragogy to a lesser extent, (see Table 1.1), are traditionally curricula driven and instructor-led; heutagogy is touted as a truly learner-centered approach where the learner has total control over the learning process.

Blaschke (2012), writing about lifelong and self-directed learning, illustrates the continuum between heutagogy and andragogy (see: Table 1).

Table 1. Heutagogy as a continuum of andragogy.

\begin{tabular}{|c|c|c|}
\hline Andragogy (Self-directed) & $\triangleright$ & Heutagogy (Self-determined \\
\hline Single-loop learning & $\nabla$ & Double-loop learning \\
\hline Competency development & $\nabla$ & Capability development \\
\hline $\begin{array}{l}\text { Linear design and learning ap- } \\
\text { proach }\end{array}$ & $\nabla$ & Non-linear design and learning a \\
\hline Instructor-learner directed & 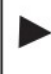 & Learner-directed \\
\hline
\end{tabular}

The emergence of Web 2.0 technologies, especially social media, as tools for learning, has generated new discussions about heutagogy. Blaschke (2012), citing McLoughlin and Lee (2007), suggests that social media, as applied to learning, is an example of one of the new tools of heutagogy, providing connectivity with others, information discovery and sharing, as well as personal curation and adaptation of information as required; these are all concrete heutogogical affordances that support self-determined and, in this case, informal learning activities. Heutagogy, as both a conceptual framework and learning strategy, is, therefore, 
well-suited to meet the needs of older adults' pursuit of informal, self-determined learning endeavours using $21^{\text {st }}$ century technological tools and processes. Heutagogy, then, best fits our exploration and understanding of how these older adults used a variety of information and communication technologies, including Web 2.0 tools to create and maintain online personal learning networks (oPLNs) to access and actualize their informal, self-determined informal learning. The ubiquity of both information (e.g., Internet-based learning resources) and the technological tools to access them (e.g., apps, mobile devices) provides unprecedented means of entry not only to these vast resources but, importantly, to other learners (e.g., via social media, online forums); oPLNs, in particular, furnishes remarkable opportunities to connect, collaborate and co-create knowledge with other older adult learners (Sharma, Palvia \& Kumar, 2017).

\section{What is informal learning?}

For the purposes of this research, formal learning is defined as any learning that takes place within an institutionally based context and is normally delivered by trained teachers in a systematic intentional way within a school or university for the purposes of credentialing. Non-formal learning includes all learning that is structured but does not have the level of curriculum and/or credentialing (Colley, Hodkinson, \& Malcom, 2002) associated with formal learning (e.g., workplace competency training, professional seminars, etc.). Finally, informal learning is any learning that is neither formal nor non-formal, is generally self-determined, has no set objectives or pre-specified learning outcomes, and may or may not be goal-directed or intentional. In this study we were focused on intentional (not incidental) informal learning; in other words, it is learner-centered, learner-driven, and is an engaging self-study processes (Baumgartner, Merriam, Cafarella, 2007), often, but not always, realized by participation in "communities of practice" (Wenger, 1998), via individual and/or communal knowledge creation rather than instructor-centered knowledge acquisition processes.

\section{Heutagogy and complexity theory}

Given the challenges of globalisation, and the rapid pace of technological change in present day ICT systems, Hase and Kenyon (2007) employ 'complexity theory' to conceptualise how learning might take place in complex adaptive systems - informal, self-determined learning being one concrete example. An in-depth exploration of complexity theory is beyond the scope of this paper but its central tenet, especially with reference to heutagogical learning, is worth considering: proponents of complexity theory argue that, unlike machines, human systems cannot be understood by reducing them to the sum of their parts (Mitchell, 2014), suggesting that complex human systems have the capacity to undergo spontaneous self-organization that is neither explainable nor predictable. Given this claim, it is, therefore, not possible to use linear, reductionist methods to predict learner/learning behaviour in complex learning environments (Doolittle, 2014); one of the reasons for this, in complex learning environments such as informal, self-determined learning contexts (as opposed to curricula-driven, outcomes-based learning), is that it is not possible to measure or control all the complex and multiple variables that affect informal learning (Anderson, 2010). 


\section{Macrothink

Complexity theory, as a central tenet of heutagogy, instead seeks to provide a conceptual framework through which to understand spontaneously created learning ecologies (Jackson, 2013) that allow effective learning behaviours to emerge naturally and ineffective ones to attenuate. At the individual level, complexity theory is activated when learners become acquainted with and recognise the constructs that both support and impede their learning and, in so doing, allows them to thrive in complex and evolving ecologies of learning. This idea is at the heart of complexity theory and serves to elucidate why Hase and Kenyon (2003) advocate for learning that is "natural," not contrived, and is, as they define it, fundamentally self-determined (Ryan \& Deci, 2000); Hase \& Kenyon, (2003, p. 3) list a number of core characteristics of complexity theory applied to heutagogical learning contexts; the following are most relevant to our explicit (and implicit) discussion here, to include:

- the dynamic nature of learning

- uncertainty about content and the importance of process

- the need to access tacit learning

- double loop learning to modify mental models;

- importance of relationships and interaction

- ability to be open to serendipitous learning

- being open to knowing

- diversity of thought

- $\quad$ and the ability to cope with ambiguity and competing ideas.

The above list of heutagogical characteristics listed above cannot all be addressed within the confines of this paper, a few are selected for commentary below.

\section{The dynamic nature of learning}

A core concept of heutagogy is developing a person's natural capacity to learn; many refer to this phenomenon as developing capability, defined as a person's ability to operate effectively in both familiar and unfamiliar situations (Cairns 1996; Hase \& Kenyon 2000; Hase \& Davis 1999; Phelps, Hase \& Ellis 2005; Stephenson, 1996; all cited in Hase \& Tay, 2006). Within heutagogy, an important distinction is made between competence and capability as differences in the ability to deal with the familiar and unfamiliar, respectively. For capability to develop the learner must be able to take charge of their learning by negotiating what will be learned and how it will be learned, as well as be able to self-reflect on the learning process in a meaningful way (Hase \& Tays, 2006); capability, then, is seen as a holistic approach that consists of the following attributes:

- use "how to learn" competencies in both familiar and novel situations;

- reflect on the learning process; 
- learn from and with others;

- have high self-efficacy.

Borrowing from Bhoryrub, Hurley, Neilson, Ramsay, and Smith (2010), Blaschke (2012) offers the following concise recap:

When learners are competent, they demonstrate the acquisition of knowledge and skills; skills can be repeated, and knowledge retrieved. When learners are capable, skills and knowledge can be reproduced in unfamiliar situations. Capability is then the extension of one's own competence, and without competency there cannot be capability. Through the process of double-looping, learners become more aware of their preferred learning style and can easily adapt new learning situations to their learning styles, thus making them more capable learners. With its dual focus on competencies and capability, heutagogy moves educators a step closer toward better addressing the needs of adult learners in complex and changing work environments (p. 60).

\section{Double-loop learning}

As mentioned above, two core components of the heutagogical learning process involve self-reflection and self-regulation. Argyris' and Schon's (1996) concept of 'double loop learning' is employed within heutagogy to define an iterative process that requires the learner to take charge of their learning by negotiating what will be learned, how it will be learned and to constantly reflect on the learning process. In double loop learning, the learner reflects not only on their actions, but also on their values and beliefs (Argyris \& Schön, 1996, as cited in Hase \& Kenyon, 2000); the learner, then, evaluates the appropriateness of their self-determined learning actions and outcomes, involving the cognitive action of reflection on values and norms and, by implication, the social structures within which the learning action takes place to be rendered meaningful (Argyris \& Schon, 1974). By contrast, formal learning is predicated on single loop learning, where the learner is directed by curricular outcomes, rubrics, etc.; they may be afforded the opportunity to search for alternative means to achieve the same end, but the goals and outcomes are "preset" by the instructional process. Heutagogy, by incorporating double-loop learning, is a holistic form of self-determined learning that improves a learner's capacity to learn and to use their competencies in both familiar and unfamiliar situations. It encourages self-reflection, not just on one's actions but within the action as well (Schon 1983, 1987 as cited in Greenwood, 1998).

\section{Heutagogy, informal learning and self-determined learning}

The idea of developing learner capability, a core tenet of heutagogy, lends itself well to the activities and processes of older adults' informal, self-determined lifelong learning. As an extension of andragogy (Blaschke, 2012), heutagogy builds on learner self-determination and autonomy and presumes that learning can be completely independent of an instructor or institution; it recognizes the importance of acquiring knowledge and skills but independent of teacher or curriculum-centric approaches. Moreover, heutagogy emphasises the need for, 'knowledge sharing' rather than 'knowledge hoarding' (Ford, 1997, in Hase \& Kenyon, 2000). In our current digital information age where access to information is, for the most part, free 
and plentiful, despite our preconceived notions and stereotypes, older adult learners are capable of being fully self-determined, of directing their own learning paths and of taking an active, rather than passive, role in their individual learning experiences; this is the essence of self-determined, informal learning. Our research has shown that the potential for some older adult learners to activate these core aspects of heutagogy in their daily informal, self-determined learning pursuits, is significant and points to a heutagogical framework as a source of personal empowerment and learner autonomy.

\section{Key affordances of Web 2.0 for heutagogical learning}

Blaschke (2012) suggests that the growing ubiquity of Web 2.0 and the use of social media in learning settings have enabled heutagogy to be more fully realized; she adds that online learning is perfectly poised to exploit the principles of heutagogy because of its symbiotic relationship with technology and its promotion of learner autonomy. In a series of early papers, McLoughlin and Lee $(2007,2008,2010)$ echo Blaschke's $(2012)$ thesis and outline how this might happen in practice: used appropriately, they suggest, Web 2.0 tools can shift control to the learner and promote learner agency and autonomy, as well as active engagement in social learning networks (e.g., oPLNs), independent of physical, geographic, institutional and organisational boundaries. We argue, in line with McLoughlin \& Lee, 2007, in Blaschke, 2012, that key affordances of oPLNs, those that specifically support self-determined learning activities include: connectivity with others, reciprocal information discovery and sharing, and personal collection and adaptation of information. Anderson (2010) lists a number of sequential affordances of Web 2.0 tools that make a heutagogical approach to older adults' learning possible: the capacity for powerful yet relatively inexpensive mobile communication devices (e.g., laptops, smartphones, tablets) and platforms (e.g., learning apps; special interest fora) enabling learners to seek and share information and resources easily, which, in turn, can more easily create a learner-organised support system (like an oPLN); in turn, these specific affordances may further enable collaborative informal, self-determined lifelong learning opportunities (Koper \& Tattersall, 2004 in Anderson, 2010). The core "dovetail" affordance to the above is a shift from information and content scarcity to abundance (Anderson, 2010), providing content in varied formats and the capacity for learners to add user-generated content via their oPLNs.

\section{Findings}

During 2015-2017, a study was conducted with the purpose of exploring older adults' use of the Internet, to include online resources, and the use of social media, to activate and maintain online personal learning networks (oPLNs), for the purposes of expanding and enriching their informal, self-directed learning goals; these were limited to informal learning goals specific to their hobbies and/or interests. Using a mixed methodology, Phase 1 of the research project used a national survey, distributed across Canada (all Provinces and Territories represented) to 365 retired older adults, age 55+, to identify ICT tools and processes they used and to explore the nature of their oPLNs employed to facilitate extended and expanded knowledge of their hobby and/or interest area. Phase 2 used an online focus group methodology (Morrison, Kristenwald, \& Tang, 2019), employing the WebEx synchronous 
web-conferencing tool, to explore participants' perceptions of the nature and value of their informal online learning activities, with a focus on their oPLNs; this qualitative approach allowed the researchers to more deeply investigate heutagogical orientations and activities critical to meaningful, self-determined online informal learning. Upon analysis, we discovered a number of findings that clearly provided evidence to heutagogical processes being activated and employed by these older adult online learners. In brief, findings below are extracted from our online focus groups with 14 self-selected participants (from the Phase I survey group); following a qualitative contextual thematic analysis of the substantive transcript (i.e., 65,000 words), we used a two-stage descriptive coding process, focused on semantic meanings, followed by iterative analytic coding, using multiple coders (coding comparison queries revealed that we had established 'good' reliability (i.e., Kappa coefficients of 0.4 or above), which focused on organizing higher-order categories, based on latent meanings from the resultant, emergent descriptive sub-themes. The granular details of the findings of these analyses are beyond the scope of this paper; however, Table 2 below presents a short summary of the three-tier hierarchy of themes, sub-themes and descriptors discovered via the contextual thematic analysis.

Table 2. Summary of contextual themes and sub-themes.

\begin{tabular}{|l|l|l|}
\hline Tier one: Core Themes & Tier-two: sub-themes & Tier-three: descriptors \\
\hline Learning context & $\begin{array}{l}\text { Conceptualizing oPLNs; } \\
\text { Membership rolls; online } \\
\text { learning tools }\end{array}$ & $\begin{array}{l}\text { Defining oPLNs; Perceptions of } \\
\text { self and others in oPLNs; Social } \\
\text { networking sites, } \\
\text { information/media types }\end{array}$ \\
\hline Learning goals & $\begin{array}{l}\text { Knowledge-centered goals; } \\
\text { experience-centered goals }\end{array}$ & $\begin{array}{l}\text { Obtaining information, learning } \\
\text { a skill, problem-solving; } \\
\text { Performing and activity, } \\
\text { sharing with others }\end{array}$ \\
\hline Motivations for learning & $\begin{array}{l}\text { Individual-centered; } \\
\text { event-centered; negative } \\
\text { influences on learning } \\
\text { motivation }\end{array}$ & $\begin{array}{l}\text { Authentic topic of interest; } \\
\text { Desire to learn and personal } \\
\text { development; attitudes or } \\
\text { beliefs }\end{array}$ \\
\hline Managing learning & $\begin{array}{l}\text { Credibility; Interaction; Search } \\
\text { strategies; barriers to managing } \\
\text { learning }\end{array}$ & $\begin{array}{l}\text { Definitions and use of } \\
\text { validation; individual and } \\
\text { referential strategies; } \\
\text { Interaction; Exploration, } \\
\text { individual techniques; Learning } \\
\text { preferences, using the Internet, } \\
\text { finding and sorting information }\end{array}$ \\
\hline Role of online learning with & Perceiving people as key \\
\hline
\end{tabular}




\begin{tabular}{|l|l|l|}
\hline learning & $\begin{array}{l}\text { others; Role of Internet on } \\
\text { learning; Valuing online } \\
\text { learning; Impact on learning } \\
\text { attitudes }\end{array}$ & $\begin{array}{l}\text { informants; Learning to use the } \\
\text { Internet and resources, access to } \\
\text { alternative perspectives to } \\
\text { expand learning; Preferences } \\
\text { for online and offline learning; } \\
\text { open-mindedness, self-directed } \\
\text { learning, valuing informal } \\
\text { learning }\end{array}$ \\
\hline $\begin{array}{l}\text { Impacts of informal learning on } \\
\text { personal and community }\end{array}$ & $\begin{array}{l}\text { Individual or personal impacts; } \\
\text { Perceptions of community or } \\
\text { connected society }\end{array}$ & $\begin{array}{l}\text { Personal interaction, } \\
\text { relationships, attitude, } \\
\text { behaviour and mental health } \\
\text { impacts; Life and } \\
\text { developmental transitions }\end{array}$ \\
\hline
\end{tabular}

\section{Participant transcript examples}

A complete description of participants' coded verbatim comments for each and every theme, subtheme, and descriptor subthemes is beyond the scope and purpose of this paper; therefore, samples are extracted to provide the reader with a sense of the types of responses utilized for qualtiative analysis. For ease of presentation, we have listed these below using the following nomenclature information structure:

Theme/subtheme/descriptor: category, followed by an epitome example.

Learning context/online role in oPLNs/descriptor: perceptions of self and others in oPLNS

Between our sessions the lady who convenes the group will frequently send out information that's coming out on the web. 'By the way this new thing is coming out. You might want to look at this.' And sometimes it's three or four conveners amongst us. We'll get together and have a more advanced session amongst ourselves to try and learn new stuff, and again communicate by email. (Interview \#3 Participant)

Learning goals/knowledge-centered goals/descriptor: sharing with others

[T] he point for me in terms of doing research about music online is to share experiences and learning about what are the best ways in order to tackle some of these kinds of compositions that we play. (Focus Group \#4, Participant \#3)

Motivations for learning/desire to learn \& personal development/descriptor: maintaining an active mind

Trying to keep my mind busy. Because I think the more that you're stimulated the more, the better you can be as far as keeping yourself brain healthy. [...] It keeps you sharper. (Interview \#1 Participant)

Managing learning/Interaction/descriptor: reciprocity 
I've mentored about eight people and this is over a long period of time. They've mentored me forever. (Interview \#4 Participant)

Impacts of oPLNs on informal learning/Impacts on learning attitudes/descriptors: self-determined learning

I really like it because it makes me more independent as a learner, but I also limit what I look at to learn. (Interview \#5, Participant)

In the Discussion below, we have selected a few of these epitome findings to highlight relevance to and provide evidence for our case that these older adults' oPLNs provided manifest "sites for heutagogy" to become activated.

\section{Discussion}

\section{Capability and self-determination in a complex system}

As defined earlier, capability within a heutagogical framework is seen as a person's ability to operate effectively in both familiar and unfamiliar situations (Blascke, 2015). Given the ubiquitous access to the ICT devices and processes indicated above, in addition to providing and gaining access to content in varied formats (e.g., YouTube videos, special interest apps and learning forums, etc.), the capacity for learners to add user-generated content, via their oPLNs, which all reported doing, is the most relevant to alignment with heutagogical principles.

Phase 1 of this research clearly indicated a wide use of ICT tools (e.g., desktops, laptops, tablets and smartphones) and processes to access the Internet to build and maintain their oPLNs. Providing a more in-depth analysis, it was clear from our qualitative data that these specific older adults were actively engaging in their oPLNs for the purposes of learning more about their hobby and/or interest; they were capable of and demonstrated being fully self-determined, of directing their own learning paths and of taking an active, rather than passive, role in their individual learning experiences. Also, in line with McLoughlin and Lee, 2007, (in Blaschke, 2012) there was extensive evidence of connectivity with others, reciprocal information discovery and sharing, and personal collection and adaptation of information for their informal learning purposes. Finally, additional characteristics of capability, as a holistic approach embedded within heutagogy (Hase and Tays, 2006) were demonstrated by these older adults', namely: the capacity of knowing how to learn; being able to reflect on the learning process; working well with others; having high self-efficacy; and being able to be creative.

\section{Complexity theory applied}

The central tenets of complexity theory, applied to this heutagogical learning context, were verified by participants' self-reporting of their online learning activities and processes. For example, their learning actions within and regular access of their oPLNs reflected the dynamic nature of their learning. Without exception, all focus group participants echoed being open to knowing and serendipitous learning, accessing tacit knowledge, and alluding to double loop learning to modify their understandings. Importantly, they emphasized the 
centrality of process and the importance of relationships and interactions with others to increase diversity of thought and to cope with competing ideas.

\section{Learner autonomy}

Heutagogy, touted as a truly learner-centered approach, where the learner has total control of or autonomy over the learning process, was reflected in this context of these older adults' informal, self-determined learning activities. It was clear that these older adults were exercising autonomy over their learning within a dynamic and complex system (Hase \& Kenyon, 2003), namely, their oPLNs; they would learn when ready and motivated, not when an external curriculum dictated. Additional capability complexities and nuances in line with heutagogy and autonomy (Hase \& Kenyon, 2003), reflected in the active participation in their oPLNs included:

- A focus on learning, not just acquisition of knowledge and skills;

- double loop learning to modify mental models;

- the importance of relationships and interaction;

- the ability to recognise and be open to serendipitous learning;

- $\quad$ presence of persuasion, argument and critical thinking;

- diversity and agility of thought;

- $\quad$ and the ability to cope with ambiguity and competing ideas (p. 3).

Of special mention here, it was clear that double loop learning was taking place, with older adult online learners reflecting not only on their actions, but on their values and beliefs as well (Argyris \& Schön, 1996, as cited in Hase \& Kenyon, 2000); most older adults interviewed evaluated the appropriateness of their learning actions and outcomes, as well as the validity and reliability of information they curated via their oPLNs. This phenomenon was an iterative process that required the learner to take charge of their learning by negotiating not only what they learned but how they learned it as well (e.g., consumption of various media types). A constant evaluation and reflection on the learning processes and content of their learning was also evident. This is a compelling connection to informal learning precepts, where learners have autonomy over their own learning, in turn, facilitating double-loop learning (i.e., learner, not curriculum-centered, as in most formal learning contexts).

\section{Intrinsic motivation and learner regulation of informal learning}

Deci and Ryan (2002) and Deci et al., (1994) refer to the internalization process of motivation as a continuum, moving from amotivation to extrinsic motivation and finally to intrinsic motivation. In concert with the locus of motivation shifts, learner regulation moves from non-regulation to external regulation and then intrinsic regulation, while behaviour shifts from non-self-determined to fully self-determined. The end of the continuum, of most 
relevance here, has learners identifying with, integrating, and then internalizing regulation of their actions, with their value and belief systems about the nature of informal learning, and entering into a state where they regulate their learning actions intrinsically (Deci \& Ryan, 2002). In every case, individuals who engaged in their oPLNs to investigate and learn more about their hobby or interest, reflected a "growth mindset" (Dweck, 2015). In other words, they were unanimous in a sentiment reflective of their desire to grow as learners, to keep their minds active and to stay connected with their circle of like-minded "colleagues."

In addition, the participants indicated they activate both convergent and divergent thinking skills when pursuing their hobby or interest. Some, while identifying as relative experts in the area, were open to new ideas, even being challenged by questions coming from so-called novices. While convergent thinking skills helped the learners to narrow their foci when they needed to go "deeper" in an arena of inquiry, they were clear that divergent thinking was equally important, to keep "an open mind" to new information and perspectives.

\section{Ubiquitous ICT tools and processes}

As stated earlier, Blaschke $(2012 ; 2015)$ claims that online learning is perfectly poised to exploit the principles of heutagogy because of its symbiotic relationship with technology and its promotion of learner autonomy. Phase 1 of this research clearly indicated a wide use of Web 2.0 tools and processes, including the use of social media to access the Internet and, more importantly, to build and maintain oPLNs in support of their informal, self-determined learning goals relevant to their particular hobby or interest. It is clear that the relative ubiquity of these ICT tools (desktops, laptops, mobile devices) made possible the learner autonomy employed by these adult learners, that these tools are prerequisite to any promotion of learner agency, the key affordance being the presence of algorithms (autonomous agents) that help "gather, aggregate, synthesise and filter the web for content that is relevant to individuals and groups of learners" (Anderson, 2004, in Veletsianos, 2010, p.31). In other words, learners were able to access and activate the key affordances of technology to activate a self-determined way to learn about their hobby or interest. Thinking of these tools as "portals" into the vast resources of the Internet as we know it, they provide a shift from "information and content scarcity to abundance" (Anderson, 2010, p. 31).

\section{Extending heutagogy: Conjoining the metaphor of ecologies of learning}

While it is clear from the preceding review of the qualitative analysis results that the conceptual lens of heutagogy is one of great usefulness to deconstruct and understand learner agency within a complex environment such as older adults' use of oPLNs to enrich their informal learning, it provides only a partial analysis [explanation] of the spontaneous and self-organising nature of such informal learning environments. Given this complexity and the characteristics of this particular informal, self-directed learning environment, however, we assert that in order to provide a more holistic understanding of such phenomena, a wider view needs to be taken, necessitating the search for an apt and rich metaphor, in our view, the learning ecology metaphor. According to Jackson (2013) the learning ecology metaphor "...has been applied to many contexts and is well suited to human interactions between people and their environment, their processes for doing, learning and achieving, and for developing 
new knowledge in unstructured contexts" (p. 1). In our case, the older adults' oPLNs, comprising unique processes and "set of contexts, relationships and interactions that provide opportunities and resources for learning, development and achievement" (Jackson, 2013, p. 1) are an epitome example of individual and collective learning ecologies. The online nature of oPLNs provide "the temporal and spatial dimensions to connect different virtual spaces and contexts, sometimes existing simultaneously across a learner's life-course" (Jackson, 2013, p. 1). Further, Gibson and Pick (2000) claim that a core characteristic of a biological ecology is that it is a self-regulating system that consumes and recycles resources; given that the older adults' activities within their oPLNs were both self-regulated (i.e., self-determined) and included learning activities that both consumed and provided resources (i.e., a level of informational reciprocity), the validity of the ecology of learning metaphor for this context is sustained. While focused on applications within higher education, Travin (2015) highlights a core characteristic of "ecosystems for learning" embedded in the older adults' oPLNs, namely, the framework itself is a personalized and self-sustaining ecosystem for learning that includes concepts of choice and access and moves the entire system forward. The dovetail with heutagogy and informal learning is also reflected in learning ecology's emphasis on technology-mediated learning where the claim is: "the line is often blurred between accessing online resources for pleasure or purpose." (B.C. Campus, p.1). The claim here is that the Internet itself is a prime substrate of an effective learning ecology, where learners can discover immediate answers from a wide variety of sources, accessing curated or non-curated repositories of relevant resources that support the informal learners' goals and interests. This can, in turn, lead to a radical increase in learner choice, autonomy and control over their own learning. So, an ecology of learning model necessarily frames learner choice and community (i.e., spanning the spectrum from one-to-one coaching or mentoring (Megginson, 2006) to many-to-many social learning (Bandura, 1962) and communities of practice (Wenger \& Wenger, 2015)) as core constituents; that these core elements were identified as key characteristics of the adult learners' learning, within the context of oPLNs should come as no surprise and further strengthens our argument that a conjoining of heutagogy and learning ecologies is a legitimate intellectual exercise to more clearly understand complex phenomena such as online informal, self-determined learning.

\section{Implications for informal, self-determined older adults' lifelong learning}

We, like Ryan and Deci (2000) “...assume people have a primary propensity to forge interconnections among aspects of their own psyches as well as with other individuals and groups in their social worlds" (p. 5). The complexity of relationships demonstrated in the learning ecology of the oPLNs within which our participants operated was quite striking. For example, many indicated that while their oPLNs were critical to connecting them with other content and learners on the Internet; some underscored the fact that they also brought any new knowledge gleaned from their online activities into their circle of face-to-face contacts and connections (e.g., local weaving club). While this research was focused exclusively on older adults' use of their oPLNs to expand their access to online learning resources and connections with other learners, it is interesting that at least some saw their activity extending 
into place-based contexts, thereby indicating a wider perspective regarding the nature of ecologies of learning, expanding the "territory" beyond online environments.

\section{Limitations}

Participants in this study were limited to those willing to participate in the online focus groups, gathered from the 365 online survey participants; given the description and purposes of the study, these 14 self-selected individuals are likely not a representative cross-section of the older adult population. However, as self-identified "adopters" of ICT technologies and processes to enhance their informal, self-directed learning goals, there is internal validity of the findings particular to this cohort of participants. Given the mixed methodology employed, questions regarding the general population of older adults' online tools and methods for informal learning must remain speculative at best; interviews with a wider spectrum of older adults, conducted, say in face-to-face focus group settings, may result in different findings, especially regarding ubiquity of ICT and their use for the purposes of informal learning amongst the general population of older adults (esp. 65+).

\section{Conclusions and Further Research}

As we have seen, heutagogy is an established and helpful conceptual framework that provides a new vision for learning in the 21st century, building on theories of humanism, constructivism, complexity theory and most recently, connectivism and the neuroscience of learning (Hase, 2016). There is opportunity to employ this framework to extend the examination of informal, self-determined learning, as deliberately juxtaposed to pedagogy, to extend and deepen the concept of andragogy, going beyond the simple acquisition of knowledge and skills characteristic of curricular and instructor-driven counterparts. Heutagogy, endorsing as it does capability and the promotion of learner agency as a more autonomous, self-determined way to learn, purposefully recognises the key affordances of ICT; in this regard, researchers may explore particular tools and processes (e.g., use of particular social media tools) to further investigate and articulate these affordances. Most compellingly, heutagogy can be contextualised through the dual lenses of complexity theory and ecologies of learning. If we can agree that an ecology of learning is a human, "natural" system, and is a complex, non-linear and unpredictable system, then learning is about analyzing, synthesising and self-determination within this system; this ecological perspective on the nature of learning in the 21 st century is in contrast to "industrial era" learning approaches (i.e, traditional, teacher/curriculum-centric), making it possible to re-conceptualise changes that might be necessary in the way we understand and facilitate learning generally. Ironically, it may be that older adults' informal, self-determined learning activities and processes, harnessing the power of heutagogy within these new ecologies of learning, may point the way to the possibility of a potential paradigm shift, if you will, that demands we think of learning differently, and that makes reimagining formal education possible, in turn, allowing us to take full advantage of the information age and all its affordances. Recently, Blaschke and Hase (2015) underscored this perspective:

"We are in the age of knowledge and skill emancipation. There are no barriers to knowing, and the skills required to be an effective learner in the twenty-first century have changed 
dramatically, as the learner evolves from passive recipient to analyst and synthesizer. On Bloom's taxonomy, these are levels that are rarely reached in formal education. Now, they are vital skills for survival in a complex environment where knowledge management, or what is now called curating, is more important than access" (p78).

Finally, we are in agreement with Travin (2015) in her claim that: "We no longer look into technology for answers, but we look through it to see and understand our world" (p. 1). Through our continued collective research into technology-mediated, heutagogically-based processes, we can further elucidate our understanding of online learning ecologies, with great potential to impact formal, non-formal and informal learning activities and systems. Finally, we respond to Dweck's (2009) question "who will the 21st-century learners be?" by answering: older adults who pursue informal, self-determined online learning should, most definitely, be included!

\section{References}

Alexander, B. (2006). A new wave of innovation for teaching and learning? EDUCAUSE Review, 41(2), 32-44. Retrieved April, 2018 from https://er.educause.edu/articles/2006/1/web-20-a-new-wave-of-innovation-for-teaching-and-1 earning

Anderson, M., \& Perrin, A. (2017a). Tech Adoption Climbs Among Older Americans. Retrieved October, $\quad 2018$ from http://www.pewinternet.org/2017/05/17/tech-adoption-climbs-among-older-adults/

Anderson, M., \& Perrin, A. (2017b). Technology use among seniors. Retrieved October, 2018 from http://www.pewinternet.org/2017/05/17/technology-use-among-seniors/

Anderson, T. (2010). Theories for learning with emerging technologies. Emerging Technologies in Distance 23-39. https://doi.org/10.15215/aupress/9781771991490.01

Argyris, C., \& Schon, D. A. (1974). Theory in practice: Increasing professional effectiveness. Oxford, England: Jossey-Bass.

Argyris, C. \& Schon, D. (1996) Organizational Learning II: Theory, method, and practice. Reading, Mass., Addison-Wesley, 86 pgs.

Bandura, A. (1962). Social learning through imitation. In M. R. Jones (Ed.), Nebraska Symposium on Motivation, Oxford, England: Univer. Nebraska Press, pp. 211-274.

Blanschke, L. (2012). Heutagogy and lifelong learning: A review of heutagogical practice and self-determined learning. International Review of Research in Open and Distance Learning, 13(1), 56-71. https://doi.org/10.19173/irrodl.v13i1.1076

B.C. Campus (2015). The learning ecology framework: Moving from instructor to learner control. Retrieved August 2018 from: https://bccampus.ca/2015/06/23/the-learning-ecology-framework-moving-from-instructor-co ntrol-to-learner-control/ 
Blaschke, L., \& Hase, S. (2015). Heutagogy, Technology, and Lifelong Learning for Professional and Part-Time Learners. In Transformative Perspectives and Processes in Higher Education, pp. 75-94. Cham: Springer International Publishing. https://doi.org/10.1007/978-3-319-09247-8_5

Blaschke, L., \& Hase, S. (2016). Heutagogy: A Holistic Framework for Creating Twenty-First-Century Self-determined Learners. In M. M. Begoña Gros, Kinshuk (Ed.), The Future of Ubiquitous Learning, 25-40. Springer Berlin Heidelberg. https://doi.org/10.1007/978-3-662-47724-3_2

Blaschke, L. M. (2012). Heutagogy and lifelong learning: A review of heutagogical practice and self-determined learning. International Review of Research in Open and Distance Learning, pp. 57-71. https://doi.org/10.19173/irrodl.v13i1.1076

Bhoryrub, J., Hurley, J., Neilson, G.R., Ramsay, M., \& Smith, M. (2010). Heutagogy: An alternative practice based learning approach. Nurse Education in Practice, 10(6), 322-326. https://doi.org/10.1016/j.nepr.2010.05.001

Cormode, G. \& Krishnamurthy, B. (2008). Key differences between Web 1.0 and Web 2.0. First Monday, 13(6). https://doi.org/10.5210/fm.v13i6.2125

Doolittle, P. E. (2014). Complex Constructivism: A Theoretical Model of Complexity and Cognition. International Journal of Teaching and Learning in Higher Education, 26(3), 485-498. Retrieved from http://files.eric.ed.gov/fulltext/EJ1060852.pdf

Dweck, C. (2015). Carol Dweck revisits the growth mindset. Education Week, 35(5), 20.

Caffarella, R. S. (1993). Self-directed learning. In: New Directions for Adult \& Continuing Education, Wiley. https://doi.org/10.1002/ace.36719935705

Deci, E. L.L. (2000). The "what" and "why" of goal pursuits: Human needs and the self-determination of behavior. Psychological Inquiry, 11(4), 227-268. https://doi.org/10.1207/S15327965PLI1104_01

Dyens, O. (2014). How artificial intelligence is about to disrupt higher education. Retrieved May, 2016, from http://www.universityaffairs.ca/features/feature-article/how-artificial-intelligence-is-about-todisrupt-higher-education/

Gersteing, J. (2018). User Generated Education: Education 3.0 and the Pedagogy (Andragogy, Heutagogy) of Mobile Learning. Retrieved April, 2018, from: https://usergeneratededucation.wordpress.com/2013/05/13/education-3-0-and-the-pedagogy-a ndragogy-heutagogy-of-mobile-learning/

Gibson, E. J. \& Pick, A. D. (2000). An Ecological Approach to Perceptual Learning and Development, New York, NY: Oxford University Press, pp. 14-26.

Greenwood, J. (1998). The role of reflection in single and double loop learning. Journal of Advanced Nursing, 27(5), 1048-1053. https://doi.org/10.1046/j.1365-2648.1998.00579.x 
Greenwood, S., Perrin, A., \& Duggan, M. (2017, May 18). Demographics of Social Media Users in 2016. Retrieved September 2018) from http://www.pewinternet.org/2016/11/11/social-media-update-2016/

Hase, S. (2016). Self-determined Learning ( heutagogy ): Where Have We Come Since 2000 ?, (May). Retrieved from https://www.researchgate.net/publication/305778049_Self-determined_Learning_heutagogy_ Where_Have_We_Come_Since_2000

Hase, S., \& Kenyon, C. (2000). From Andragogy to Heutagogy. ultiBASE. Retrieved from http://ultibase.rmit.edu.au/Articles/dec00/hase2.htm

Hase, S., \& Kenyon, C. (2003). Heutagogy and developing capable people and capable workplaces: strategies for dealing with complexity, pp. 25-27. Retrieved from epubs.scu.edu.au/cgi/viewcontent.cgi? article $=1123 \&$ context $=\mathrm{gcm} \_$pubs

Hase, S., \& Kenyon, C. (2007). Heutagogy: A Child of Complexity Theory. Complicity: An International Journal of Complexity and Education, 4(1), 111-118. https://doi.org/10.29173/cmplct8766

Hase, S., \& Tay, B. H. (2006). Developing learner capability through action research: From pedagogy to heutagogy in the workplace. Proceedings of Global VET: Challenges at the Global, National and Local Levels: Australian Vocational Education and Training Research Association (AVETRA) Conference, pp. 1-10. Retrieved May, 2018 from: http://epubs.scu.edu.au/cgi/viewcontent.cgi?article $=1135 \&$ context $=\mathrm{gcm} \_$pubs

Helper, E. J. \& Enyon, R. (2013). Digital natives: Where is the evidence? British Educational Research Journal, 36(3), 503-520. https://doi.org/10.1080/01411920902989227

Heuristic | Define Heuristic at Dictionary.com. (n.d.). Retrieved September, 2017, from http://www.dictionary.com/browse/heuristic

Jackson, N. (2013). The concept of learning ecologies. Lifewide Learning, Education \& Personal Development (e-book). Retrieved from: http://www.lifewideebook.co.uk/uploads/1/0/8/4/10842717/chapter_a5.pdf

Kinshuk, N.S. C, Cheng, I. L., \& Chew, S.W. (2016). Evolution Is not enough: Revolutionizing Current Learning Environments to Smart Learning Environments, International Journal of Artificial Intelligence in Education, 26(2), 561. https://doi.org/10.1007/s40593-016-0108-x

Meggison, D. (2006). Mentoring in action: A practical guide (2nd ed.). Development and Learning in Organizations: An International Journal, 20(5). https://doi.org/10.1108/dlo.2006.08120eae.001

McLoughlin, C., \& Lee, M. J. W. (2007). Social software and participatory learning: Extending pedagogical choices with technology affordance in the Web 2.0 era. In ASCILITE 2007: ICT: Providing choices for learners and learning, 24th Annual Conference of the 
Australasian Society for Computers in Learning in Tertiary Education, pp. 664-675. http://www.ascilite.org.au/conferences/singapore07/procs/mcloughlin.pdf

McLoughlin, C., \& Lee, M. J. W. (2008). The three P's of pedagogy for the networked society: Personalization, participation, and productivity. International Journal of Teaching and Learning in Higher Education, 20(1), pp. 10-27.

McLoughlin, C., \& Lee, M. J. W. (2010). Personalised and self regulated learning in the Web 2.0 era: International exemplars of innovative pedagogy using social software. Australasian Journal of Educational Technology, 26-43. https://doi.org/10.1523/JNEUROSCI.4255-09.2010

Medina, J. (2008). Brain rules : 12 principles for surviving and thriving at work, home, and school. (Cutchlow, T., Ed.). Seattle, WA: Pear Press.

Moravec, J. (2008). Toward Society 3.0: A New Paradigm for 21st century education. Retrieved January 2018 from: https://www.slideshare.net/moravec/toward-society-30-a-new-paradigm-for-21st-century-edu cation-presentation?type=powerpoint April 14, 2018.

Morrison, D., Kristenwald, K. \& Tang, R. (2019). Extending the online focus group method using web-based conferencing to explore older adults' online learning. (in press). International Journal of Research and Method in Education, v(i), XX. https://doi.org/10.1080/1743727X.2019.1594183

Mitchell, M. (2014). How Can the Study of Complexity Transform Our Understanding of the World? Retrieved July, 2016, from https://www.bigquestionsonline.com/2014/01/20/how-can-study-complexity-transform-our-u nderstanding-world/

O'Reilly, T. (2005). What is Web 2.0: Design patterns and business models for the next generation of software. Retrieved April, 2018 from http://www.oreilly.com/pub/a/web2/archive/what-is-web-20.html

Ryan, R. M. \& Deci, E. L. (2000). Intrinsic and extrinsic motivation: Classic definitions and new directions. Contemporary Educational Psychology, 25(1), 54-67. https://doi.org/10.1006/ceps.1999.1020

Ryan, R. M. \& Deci, E. L. (2000). Self-determination theory and the facilitation of intrinsic motivation, social development, and well-being. American Psychologist, 55(1), 68-78. https://doi.org/10.1037/0003-066X.55.1.68

Ryan, R. M. \& Deci, E.R. (2002). Overview of self-determination theory: An organismic dialectical perspective. In: Handbook of Self-determination Theory, Rochester, NY: University of Rochester Press, 449 pgs.

Sharma, S. K. Palvia, S.C.J \& Kumar, K. (2017) Changing the landscape of higher education: From standardized learning to customized learning, Journal of Information Technology Case and Application Research, 19(2), 75-80. https://doi.org/10.1080/15228053.2017.1345214 


\section{Macrothink}

Journal of Studies in Education

ISSN 2162-6952 2020, Vol. 10, No. 3

Smith, A. (2016, January 25). Older Adults and Technology Use. Retrieved October 2017 from http://www.pewinternet.org/2014/04/03/older-adults-and-technology-use/

Smith, M. K. (2002) 'Malcolm Knowles, informal adult education, self-direction and andragogy', The Encyclopedia of Informal Education, www.infed.org/thinkers/et-knowl.htm.

Techopedia. (2018). Web 3.0. Retrieved April, 2018 from https://www.techopedia.com/definition/4923/web-30

Travin, M. T. \& Hibittis, P. D. (2015). A learning ecology framework In: Anggraeni, H., The Learning Ecology Framework: Moving from Instructor Control to Learner Control, B.C. Campus News. Retrieved November, 2017 from: https://bccampus.ca/2015/06/23/the-learning-ecology-framework-moving-from-instructor-co ntrol-to-learner-control/

Veletsianos, G. (2010). Emerging technologies in distance education. Edmonton, AB: AU Press, 335 pgs.

Von Glaserfeld, E. (1989). Constructivism in education. In: T. Husen \& T. N. Postlethwaite, (eds.) (1989) The International Encyclopedia of Education, Supplement, 1. Oxford/New York: Pergamon Press, 162-163.

Weiss, R.S. \& Bass, S.A. (Eds). (2001). Challenges of the Third Age: Meaning and Purpose in Later Life. Oxford University Press, 216 pgs.

Wenger, E. \& Wenger-Trayner. (2015). Introduction to communities of practice: A brief overview of the concept and its uses. Retrieved December, 2017 from: http://wenger-trayner.com/introduction-to-communities-of-practice/ 